\title{
Limited uptake of protected area evaluation systems among managers and decision-makers in Spain and the Mediterranean Sea
}

\author{
D. Rodríguez-Rodríguez, J. Martínez-Vega, M. Tempesta and M. M. Otero-Villanueva
}

Keywords: Decision-maker, evaluation system, manager, Mediterranean Sea, protected area, Spain.

\begin{abstract}
The System areas are regarded as the main strategy to halt biodiversity loss; however, protected area effectiveness evaluations remain scarce and mostly rely on limited scientific evidence. Protected area managers from two case studies in the Mediterranean basin biodiversity hotspot (networks of Spanish terrestrial protected areas and individual Mediterranean marine protected areas) were surveyed to assess the use of two protected area evaluation systems: the 'System for the Integrated Assessment of Protected Areas' (SIAPA) and the 'System for Quick Evaluation of Management in Mediterranean MPAs' using the 'Knowledge Systems for Sustainable Development' framework. A second survey in Spain ascertained the degree of implementation of protected area evaluation systems and the institutional interest in implementing such systems. The main weaknesses attributable to the systems presented were limited salience (for the SIAPA) and legitimacy in terms of costs (for the System for Quick Evaluation of Management in Mediterranean MPAs). However, the main reasons for the limited uptake of the evaluation systems presented were not attributable to the systems themselves, but to management or institutional limitations: the lack of basic data for and weak institutional interest in evaluation in Spain, and the scarce resources available for evaluation in the case of some evaluation systems elsewhere importance of future LULC scenarios when planning fire prevention measures.
\end{abstract}

\section{Introduction}

Protected areas (PAs) are regarded as important tools for cultural values (Dudley 2008), especially in biodiversity hotspots and priority conservation areas such as the Mediterranean Sea (Myers 2000; Olson \& Dinerstein 2002). Protected area managers and decision-makers are entrusted to conserve these common goods sustainably (Deke 2008); however, the effectiveness of PAs at conserving biodiversity is contested (Ervin 2003; Mora and Sale 2011). Different studies claim disparate outcomes depending on PA characteristics (Edgar et al. 2014), biogeographical contexts (Geldmann et al. 2013; Rodríguez-Rodríguez \&Martínez-Vega 2013a), and the metrics considered (Naughton-Treves et al. 2005). Yet PA evaluation exercises remain essential for informed decision-making and adaptive management (Ervin 2003; Hockings et al. 2006).

Legal requirements to monitor and assess PAs or conservation features come from a number of regional agreements, like the Habitats Directive in Europe (EC [European Commission] 1992), and international agreements such as the Convention on Biological Diversity (CBD), acting as the overarching legal (CBD 1992) and policy (CBD 2004) framework for PAs. In 2010 , the CBD set the target of assessing $60 \%$ of the world's protected area by 2015 (CBD 2010). Scientific and management institutions have developed numerous tools to assess PA effectiveness worldwide (Leverington et al. 2010). However, by December 2012, only c. $29 \%$ of nationally designated PAs included in the World Database on Protected Areas (IUCN [International Union for the
Conservation of Nature] \& UNEP-WCMC [United Nations Environment Programme-World Conservation Monitoring Centre] 2014) had undergone some form of evaluation (Coad et al. 2013). The researchimplementation gap is a widespread and worrisome phenomenon in conservation science (Knight et al. 2008; Cook et al. 2013) leading to suboptimal management decisions and inefficient expenditure of scarce resources (Prendergast et al. 1999). A number of common grounds limiting the uptake of conservation science by practitioners and decision-makers have been cited (Prendergast et al. 1999; Briggs 2006; Knight et al. 2008). Among these, three overarching criteria are highlighted by Cash et al. (2003) in their Knowledge Systems for Sustainable Development framework: salience, credibility and legitimacy of scientific information.

In this study, we aimed to analyse the use of two PA evaluation systems by PA managers and decision-makers in the Mediterranean biodiversity hotspot, namely the System for the Integrated Assessment of Protected Areas (SIAPA; Rodríguez-Rodríguez \& Martínez-Vega 2012); and the System for Quick Evaluation of Management in Mediterranean MPAs (a WWF [World Wildlife Fund]IUCN system; Tempesta \& Otero 2013). We also aimed to test both evaluation systems, and their developmental processes, against the Knowledge Systems for Sustainable Development theoretical framework (Cash et al. 2003), to identify whether possible hindrances to the use of both systems are attributable to the systems themselves or to other reasons. 


\section{Methods}

\section{Case study 1: PA effectiveness evaluation in Spain}

At the end of 2011, there were over 1700 nationally designated PAs in Spain covering 6975351 ha, or 12.85\% of the Spanish territory on land and at sea (Múgica et al. 2012). Approximately $75 \%$ of the Spanish land territory belongs to the Mediterranean biogeographic region (Rivas-Martínez et al. 1990), most of which is classified as a global biodiversity hotspot (Myers et al. 2000). In Spain, PA management is an exclusive responsibility of each of the 19 autonomous authorities (17 autonomous regions and two autonomous cities), although the Spanish National Ministry for Environment keeps some management coordination competencies over the network of 15 national parks implemented through the National Park Autonomous Body (OAPN). The OAPN has also undertaken standardized monitoring activities in the national park network since 2004. The SIAPA was initially developed and applied to the Pas of the Autonomous Region of Madrid (Rodríguez-Rodríguez \& Martínez-Vega 2013a) and later presented as a possible standard for terrestrial PA evaluation in Spain (RodríguezRodríguez \& Martínez-Vega 2013b).

We undertook two surveys: one among PA network managers to investigate the use of the SIAPA (survey 1), and the second among decision-makers to ascertain the degree of implementation of PA effectiveness evaluations and the institutional interest in evaluating PA effectiveness in Spain (survey 2).

For survey 1, we organized a national workshop on PA effectiveness evaluation. The workshop convened representatives of research institutions, conservation organizations, regional PA network managers, the National Ministry for Environment, environmental nongovernmental organizations (NGOs), local government organizations and environmental foundations. We presented the methodology underpinning the SIAPA (Rodríguez-Rodríguez \& Martínez-Vega 2012) and circulated a structured questionnaire with mainly closedended questions on the use of the SIAPA for PA network managers to answer (see Supplementary material, Appendix 1). A measure of consensus was derived using the coefficient of variation $(\mathrm{CV})$ of the responses, the $\mathrm{CV}$ being regarded as a robust estimate of inter-observer precision or degree of agreement (Euser et al. 2008). The results of this survey reflect only the responses of workshop attendees with PA management responsibilities: 11 of the 17 regional PA network managers, plus the representative from the OAPN. Invitations to attend the workshop, as well as complete publications about the SIAPA written in Spanish (Rodríguez-Rodríguez \& Martínez-Vega 2013b), were sent to PA network managers of the 19 autonomous regions and cities and the OAPN. Although all the expenses for attending the workshop were covered, eight of the regional or city managers could not attend, declined attendance or did not reply to our invitation. We gave those who were unable to attend the opportunity to participate in the workshop remotely via
Skype or videoconference, or to complete the workshop questionnaire remotely; these offers did not increase the response rate.

The second survey (survey 2) used open- and closedended questions to elicit the status of PA effectiveness evaluation in Spain and assess the institutional interest in evaluating Pas (see Supplementary material, Appendix 2). We contacted the Director Generals responsible for biodiversity conservation and PAs from each of the 17 autonomous regions in Spain, the Director of the OAPN and the local ministers of environment of the two Spanish autonomous cities, Ceuta and Melilla, by telephone and email. Given the very low response rate to the e-mailed survey by the established deadline, we offered PA network managers the option of replying to the institutional survey themselves, with the aim of achieving a higher response rate.

Given that respondents were asked to reply on behalf of their institutions and that the survey was originally sent to the Director Generals of each institution, we assumed an institutional response to this survey.

\section{Case study 2: MPA evaluation in the northern} Mediterranean

There are more than 675 marine protected areas (MPAs) in the Mediterranean Sea covering c. 87500 ha (Gabrié et al. 2012). Despite increasing efforts, many of these MPAs do not have a management plan or a management body, have limited management capacity, and lack regular monitoring programmes and integration of local stakeholders in their management (Gabrié et al. 2012; Tempesta \& Otero 2013).

The MedPAN [The Network of Managers of Marine Protected Areas in the Mediterranean] North project's general aim was to enhance the management effectiveness of MPAs in the northern Mediterranean and contribute to the establishment of a network of MPAs (MedPAN North 2013). One of the project's objectives was to develop a harmonized methodology to help MPA managers to evaluate the effectiveness of their own management. The variety of Mediterranean MPAs, in terms of protected features, conservation objectives, stages of management and evaluation, and evaluation systems used (if any), offered the opportunity to develop a standardized methodology to be applied in the Mediterranean Sea with due representation of management contexts and conservation interests. The proposed system was developed by focusing on managers' needs and with wide MPA managers' input (Tempesta \& Otero 2013).

The WWF-IUCN system was tested on eight MPAs from four northern Mediterranean countries: Miramare MPA, Cinque Terre MPA, Torre Guaceto MPA and Tavolara-Punta Coda Cavallo MPA (Italy), Cap de Creus Nature Park and IllesMedes MPA (Spain), Strunjan Nature Reserve (Slovenia), and Tela s'cica Nature Park (Croatia). Most MPAs that took part in the evaluation are managed by either a government agency or an independent authority, and only one site is managed by an environmental organization 
Table 1

Main characteristics of both protected area evaluation systems assessed. ${ }^{a}$ Complete model of the system for the integrated assessment of protected areas (SIAPA); ${ }^{\mathrm{b}}$ simplified model of the SIAPA; ${ }^{\mathrm{p}}$ priority 1 indicators; ${ }^{\mathrm{d}}$ priority 2 indicators.

\begin{tabular}{lll}
\hline & SIAPA & WWF-IUCN system \\
\hline Reference & $\begin{array}{l}\text { Rodríguez-Rodríguez and Martínez- } \\
\text { Vega, 2012 }\end{array}$ & Tempesta and Otero, 2013 \\
\hline Type of measure & Indicators & Indicators \\
\hline Number of indicators & $43^{\mathrm{a}}$ or $28^{\mathrm{b}}$ & $18^{\mathrm{c}}$ or $12^{\mathrm{d}}$ \\
\hline Type of PA assessed & Terrestrial & Marine \\
\hline Organization carrying out the evaluation & External & Mostly internal \\
\hline Participation of managers in the development & Partial (scientifically-led) & Full (co-developed) \\
of the system & & Individual PA \\
\hline Evaluation unit & Individual PA & Yes \\
\hline Comparability & Yes & No \\
\hline Integration of results into indexes & Yes & 8 \\
\hline Protected areas assessed & 10 & Italy, Spain, Slovenia, Croatia \\
\hline Countries where it was applied & Spain & 3 \\
\hline Protected area designation categories assessed & 8 & 27 436 \\
\hline Hectares assessed & 120900 & $2012-13$ \\
\hline Date of evaluation & $2009-10$ & Protected Area managers \\
\hline Type of stakeholder surveyed & Protected Area network managers &
\end{tabular}

(Miramare MPA). The site evaluations were conducted by MPA managers (staff or co-management agencies) or by external consultants. After the evaluation was completed, we circulated a survey among the eight MPA managers who tested the system (survey 3 ). We submitted a simple questionnaire consisting of five open-ended questions to the person responsible for management evaluation in each of the eight MPAs (see Supplementary material, Appendix $3)$.

\section{Evaluation systems assessed}

We assessed two PA evaluation systems (Table 1). For this study, we followed a nested definition approach that included PA management effectiveness evaluation (Hockings et al. 2006) and PA effectiveness evaluation (Rodríguez-Rodríguez \& Martínez-Vega 2012) within the more generic PA evaluation term.

\section{Results}

\section{PA effectiveness evaluation in Spain}

Assessment of the SIAPA (survey 1)

The response rate ranged between $55 \%$ and $40 \%$, depending on the questions. Geographically, this sample of respondents covers $87.8 \%$ of the Spanish land territory and includes 1026 PAs, mostly terrestrial. These PAs represent $59.9 \%$ of the whole country's nationally designated PAs and $82.1 \%$ of the terrestrial area protected.
The main reasons for not responding to the survey or failing to attend the workshop were: 'PA effectiveness evaluation is not a priority topic', 'lack of staff', and 'lack of financial resources' to attend the workshop. The main limitations to the use of the SIAPA identified by PA network managers were: (1) limited basic information (CV $=17.05 \%),(2)$ the SIAPA is inadequate for user needs $(\mathrm{CV}=24.47 \%)$, (3) limited budget $(\mathrm{CV}=28.55 \%)$, and (4) limited institutional interest $(\mathrm{CV}=36.62 \%)$ (Table 2).

Institutional survey (survey 2)

The response rate was $45 \%$, including six regional management institutions, two local management institutions and the OAPN. The land area managed by the responding institutions amounts to $53.7 \%$ of the Spanish territory, and included 508 PAs, representing $29.7 \%$ of the country's Pas and $52.5 \%$ of the terrestrial protected area in the country. Reasons given for not responding to the survey included: 'PA effectiveness evaluation is not a priority topic', 'there is a lack of political will towards this topic', 'there is institutional fear of evaluations leading to important hindrances for sharing data and disclosing information', 'lack of sufficient staff', 'lack of financial resources', and 'internal institutional complexity hampering PA evaluation systems'.

Seventy-eight per cent of respondents were in favour of a standardized national PA evaluation system, ideally compatible with international systems. Respondents suggested that such a system would: 'reduce evaluation subjectivity', 'provide a good basis for the making of management plans', 'allow the comparison of results', 
Table 2. Results of survey 1, mean values (ranging from $1=$ completely disagree to $10=$ completely agree, except question 3 , where values were: annually; every two years; every three years; every four years; every five years; at> 5 year intervals), standard deviations (SD), and main reasons for each valuation (and solutions to limitations to the regular implementation of the system for the integrated assessment of protected areas [SIAPA], for questions 5a to $5 \mathrm{~g}$ ) given by protected area network managers in Spain. PA = protected area.

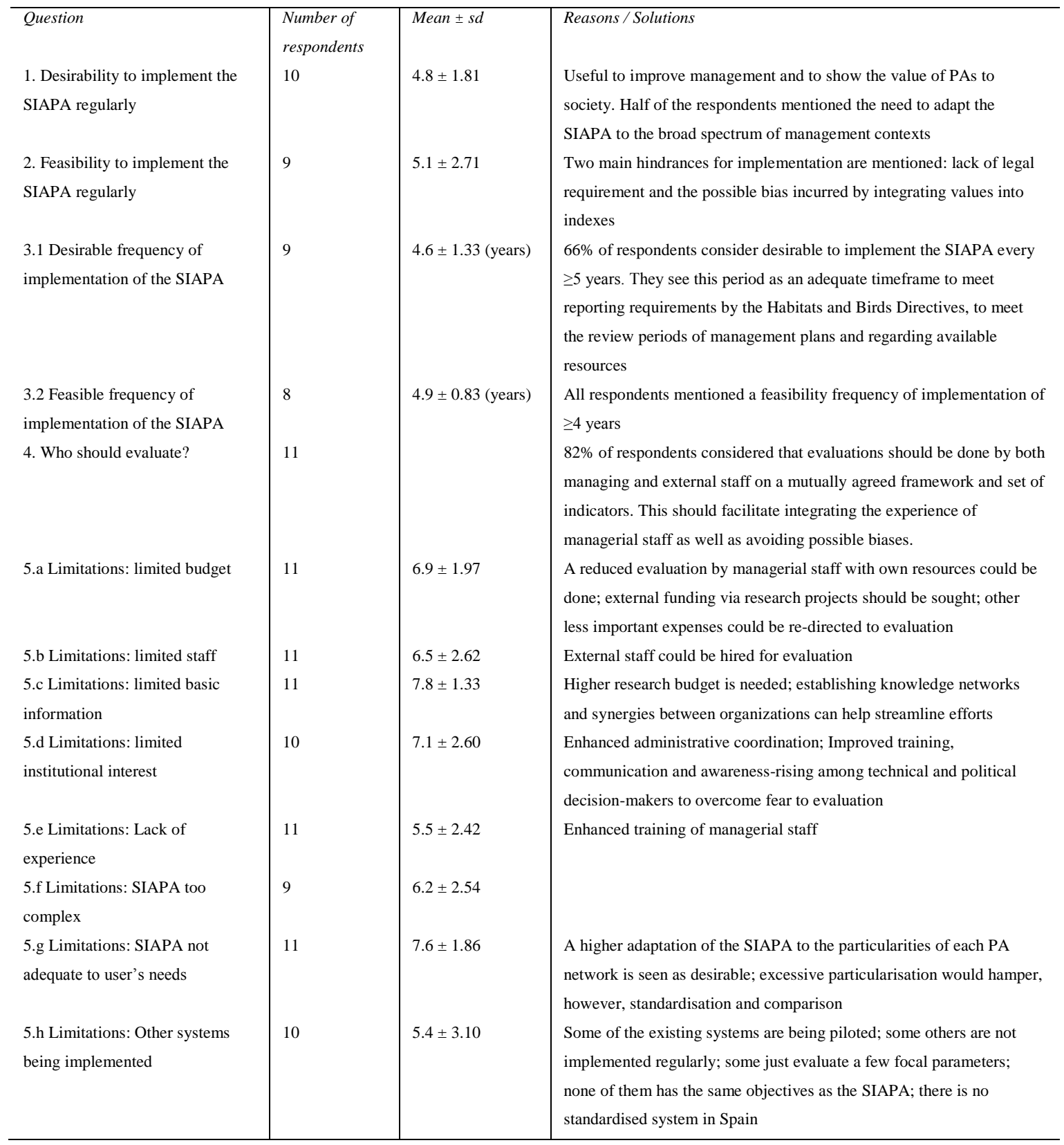

'facilitate the exchange of information', and 'permit checking the meeting of objectives for individual PAs and for the network as a whole'.

Eighty-eight per cent of respondents either did not reply or were not interested in a PA effectiveness evaluation system for their territories. Lack of salience of PA effectiveness evaluation, and limited human and financial resources were stated as the main reasons for this limited interest.
Regarding the status of PA evaluation in Spain, only $44 \%$ of respondents were undertaking any kind of regular PA evaluation, and this was mostly related to Natura 2000 sites and national parks. Most evaluations had no integrated approach and simply recorded some variables that were of interest to management, or applied to few PAs. Only the OAPN had undertaken regular, comprehensive and standardized monitoring within the network of national parks since 2004. It was also the only 
public institution in Spain that had made the results from such assessments available Limited uptake of protected area evaluation systems 241 to the public every three years (MAGRAMA [Ministerio de Agricultura, Alimentación y Medio Ambiente] 2014).

\section{MPA evaluation in the northern Mediterranean}

The response rate was $62.5 \%$, with five of the eight MPA managers providing feedback on the application of the system. From those answers, the indicators used were considered useful and a good basis for the evaluation of management effectiveness, as they encompass most of the basic elements of an MPA. One respondent said that the information needed was too complex in terms of necessary data for evaluation, while all the respondents agreed on the utility of the tool for the evaluation of management effectiveness at a regional scale.

In terms of the difficulties encountered, all managers stressed the lack of funds and personnel to dedicate to the collection of data to quantify the indicators. In some cases, a complex internal organization was highlighted, which slowed the evaluation process. For all respondents, the use of this tool in the future was conditioned by the existence of dedicated funds and projects. The existence of an adequate management plan that included MPA effectiveness evaluation was seen as being of outmost importance.

The application of the WWF-IUCN system was most useful for the MPAs that had started to implement management activities recently. For them, the indicators represented a basis upon which to build future management activities. In contrast, managers from longestablished MPAs stated the system revealed few new issues to them. The sharing of the tool among colleagues was viewed as a weakness, as all the respondents seemed to have had difficulties in agreeing its value and sharing results with other colleagues and supervisors. Whereas MPA technical staff were frequently involved in the collection of data for evaluation, they usually had little participation in or knowledge of the evaluation's outputs.

\section{DISCUSSION}

Response rates for the three surveys were comparable to other similar studies involving scientists (Knight et al. 2008) and practitioners (Pullin et al. 2004).

\section{Assessment of the evaluation systems}

When assessed against the knowledge systems framework (Cash et al. 2003), the SIAPA's main weakness was salience. The majority of the $60 \%$ of the managers who considered the PA evaluation topic important enough to reply to survey 1 deemed it inadequate to their needs due to the specific characteristics of their territories and PAs. Some mentioned that their priority at that moment was to complete adequate management plans for all PAs, including Natura 2000 sites, as legal requirements and deadlines were already in place, and that evaluation should come after that. This suggests a notable temporal mismatch between the priorities of conservation scientists on one side and those of managers and decision-makers on the other (Briggs 2006). However, the making of management plans can profit greatly from the information gathered during evaluation processes in an adaptive management cycle (Hockings et al. 2006), and thus the management sequence could arguably be the inverse (Ervin 2003; Pullin et al. 2004).

Limited salience is one of the most common causes cited for the limited uptake of science (Cook et al. 2013). The lack of PA evaluation by PA network managers in Spain can partly be explained by other compelling, legally-driven management priorities from the European Union, such as the making and approval of management plans for Natura 2000 sites. Avoiding fines for failing to meet those legal deadlines was the top priority for many managers at the time of the workshop, as some of them stated. This suggests that penalties for non-compliance with environmental standards can be an effective means of improving accountability in natural resource management. The SIAPA's limited salience could thus be partially attributed to the lax interpretation of non-punitive requirements stated in international (CBD 1992) or national law (Spanish Government 2007a) for regional and local authorities to monitor and periodically assess biodiversity, geodiversity, and ecological and geological processes. In Spain, the OAPN was the only organization that regularly monitored and publicly disclosed results, being specifically and legally bound to do so according to the requirements of National Parks Law 5/2007 (Spanish Government 2007b). Additionally, the fact that PA managers rely heavily and confidently on their own judgements and experience for evaluating PAs (Cook et al. 2010; Pullin et al. 2004) may have reduced interest in the proposed evidence based evaluation system. Finally, the SIAPA's limited salience can also partially be explained because the original SIAPA (RodríguezRodríguez \& Martínez-Vega 2012) was developed to be primarily implemented in the Autonomous Region of Madrid, a region with few socioeconomic characteristics in common with the rest of the Spanish regions (Hewitt \& Escobar 2011). The limited salience of the SIAPA contrasts with results disclosing that c. $80 \%$ of 53 Mediterranean MPA managers considered research in PA monitoring, including research on 'evaluation process of management efficacy' as 'important' or 'very important' (Di Carlo et al. 2013).

The main weakness of the WWF-IUCN system appears to be legitimacy, with insufficient funds and/or staff to implement the system regularly cited as the main hindrances for its regular implementation. For conservation science to be regarded as legitimate, it must account for restrictions on implementation (Cook et al. 2013). Some of the monitoring data needed to quantify some of the indicators were considered too costly and time-consuming to gather, while one respondent stated that the results did not reveal anything new. This could be explained by the different management stages and 
resources of the participating MPAs. Whereas data collection that diverts funds from management on the ground may not always be a good use of resources (Cook et al. 2013), lack of scientific evidence for management is likely to result in suboptimal management (Hockings et al. 2006) and conservation outcomes (Pullin et al. 2004). Insufficient financial and human resources for PA management is widespread in Europe (Nolte et al. 2010) and globally (Leverington et al. 2010), making cost legitimacy of most evaluation tools a common issue.

Credibility does not seem to have played a major role in either system. Institutional credibility was ensured by the prestige of the leading institutions, the Spanish National Research Council (for the SIAPA), and the IUCN and WWF (for the WWF-IUCN system). Personal credibility of promoters was given, if only, by the fact that all the leading researchers were $\mathrm{PhDs}$ and currently employed by research institutions or conducting research within their institutions. However, in the SIAPA case, some scientists at the workshop criticized some technical aspects of it and their limited participation in the development of the system which may have influenced its credibility and legitimacy by the managers at the workshop to some extent, as suggested by Cook et al. (2013). Nevertheless, those scientists had been consulted and offered the opportunity to participate in the development of the SIAPA at the early stages (RodríguezRodríguez \& Martínez-Vega 2012).

\section{Causes for the limited uptake of the systems}

Most of the responding decision-makers in Spain would be willing to develop a PA evaluation system for the whole country, but not a bespoke system for their regions, even if scientific and financial assistance were offered. Of the institutional responses received, only one $(5 \%$ of our sample) was interested in the development of a bespoke system. There seems to be, at best, a dysfunction between the views of PA network managers and those of decisionmakers that hampers regular PA evaluation. Whereas this nationwide stated interest may have an ecological underpinning (Pressey et al. 2007), it can also be interpreted as lack of institutional leadership and commitment around a politically-sensitive issue (Nolte $e t$ al. 2010; Cook et al. 2013). Protected area evaluations seek to improve the effectiveness, efficiency, transparency and accountability of conservation actions, and can be thus categorized as 'environmental audits' (Hockings et al. 2006). However, the principles underpinning audits, though desirable and agreeable in theory to both scientists (Hockings et al. 2006) and practitioners (Di Carlo et al. 2013), do not seem to be so easily applied in certain sociopolitical contexts, like the Mediterranean.

Financial constraints may have played an important role in the uptake of both systems. Nevertheless, both the original SIAPA and the WWF-IUCN system rely mainly on secondary data of simple analysis and interpretation, and provide a complete and simplified version of the systems, with a lower number of indicators to enhance cost-effectiveness. As a result, implementation costs of these systems should not be a major hindrance in European Union countries, although current cuts resulting from global (and some national) economic crises may compromise extra budgetary adjustments to implement such evaluations.

Survey 3 identified limited internal communication of available evaluation tools and sharing of evaluation results within management organizations as factors that may have also hampered broader knowledge and use of evaluation systems. Increased active MPA staff engagement in the evaluation process may improve the WWF-IUCN system' implementation efficacy and help to expand a culture of evaluation that promotes evaluation as an essential part of the development and implementation of the sites' management plans (Hockings et al. 2006). For this to happen, a supportive leadership that understands the importance of such assessments and communicates effectively with its staff is likely to result in broader engagement and long-term commitment to evaluation processes.

Science is also likely to have played a role in the limited uptake of PA evaluation systems. The lack of a clear and consistent definition of PA effectiveness (Rodríguez-Rodríguez 2012), the plethora of evaluation systems available (Leverington et al. 2010), concerns over these systems' accuracy, precision and degree of uncertainty (Andam et al. 2008; Cook \& Hockings 2011), and limited scientific agreement on the topic may hamper the credibility of PA evaluation systems and discourage some PA managers. Science may also be failing at conveying the salience of the topic to its target audience through inadequate communication channels and language (Cash et al. 2003; Briggs 2006). However, both the SIAPA and the WWF-IUCN system outputs were delivered to PA managers and decision makers, either as hard copies or online in their native tongue (in Spanish, for the SIAPA; in French and Italian, for the WWF-IUCN system) and in English. Additionally, specific workshops were run to present these tools to PA managers and network managers, which encourages us to largely discard the communication flaw hypothesis.

\section{Future research and recommendations}

This study raises some pertinent questions for further research that extend to broader economic and sociopolitical arenas. Is law the most effective way to increase salience among practitioners and decisionmakers? Are penalties or rewards needed to enhance PA evaluation performance? Are there other reasons why the topic of PA evaluation is not considered salient by managers and decision-makers? Is science failing to convey the importance of conducting regular PA evaluations to their final users? Should waning biodiversity not be assessed soundly and regularly because the topic is not deemed salient by some managers and/or decision-makers? Does chronic underfunding of PAs hamper regular PA evaluations by compromising the cost legitimacy of most evaluation systems with a minimal degree of complexity? Should biodiversity hotspots 
receive additional funding for improved assessment of their PAs? Should results of PA evaluations not be disclosed to taxpayers who, in addition to funding the bulk of conservation efforts, are co-owners of the valuable public goods in PAs?

Further research is needed to study and resolve the barriers to systematic PA evaluation in certain contexts, and to further develop simple, consistent, accurate, costeffective and useful evaluation tools for management. Interdisciplinary 'boundary organizations' (Cook et al. 2013) at different scales, such as the IUCN globally, the EUROPARC Federation in Europe or the MedPAN Association in the Mediterranean Sea, are existing networks aimed at bridging the science-implementation gap and can act as useful platforms to streamline future efforts in PA evaluation.

We hope this initial study may open a necessary debate on the actual use and scope of PA evaluations. No optimal PA evaluation system exists. However, imperfect systems are far better than no system at all when dealing with frail and scarce conservation features, especially if implemented regularly, so results can be compared over time. New initiatives, such as the IUCN's Green List of PAs (IUCN 2012) can incentivize PA management effectiveness evaluations and performance, especially if linked to allocation of resources or other forms of recognition. Conversely, the success of 'compulsory' PA evaluations (Coad et al. 2013), and some PA managers' recognition of the fact that most of their management actions are driven by punitive legal requirements rather than by scientific advice, raise the question of whether in order to achieve sound and systematic PA evaluations globally, a specific legally-binding mandate to do so should be put in place through relevant agreements in order to conserve valuable commons.

\section{CONCLUSIONS}

The limited uptake of both the PA evaluation systems assessed was mostly constrained by factors independent of the systems themselves: lack of basic monitoring data, and limited funds and staff available to carry out evaluations. In Spain, PA network managers are currently subject to other management priorities, making institutional support for PA evaluation weak. This is consistent with studies that identified lack of political will as the most frequent reason for governance and policy failure in diverse environmental fields (Carbonetti et al. 2014). PA evaluation in Spain is consequently still largely absent, heavily legally-driven (although with limited compliance at the regional and local scales) and restricted to certain biological features and the network of national parks, with the exception of one-off scientific initiatives (Mallarach 2008; Rodríguez-Rodriguez \& Martínez-Vega 2013b).

The knowledge systems for sustainable development framework (Cash et al. 2003) cannot explain all the causes for the low uptake of the presented PA evaluation systems by PA managers because it focuses only on the scientific side of the research-implementation equation and does not consider additional limiting factors driven by improvable management contexts: lack of basic information for evaluation, limited staff or funds to allocate to evaluation, discomfort with evaluation procedures, little institutional support, or even political opposition to evaluation (Rodríguez-Rodríguez \& Martínez-Vega 2013a).

\section{ACKNOWLEDGEMENTS}

We applied the sequence-determines-credit approach for the sequence of authors. We thank all the participants in the SIAPA and MedPAN North Project workshops for their input and collaboration, and especially those MPA managers, PA network managers and decision-makers who responded to the surveys. We also acknowledge the financial and logistical support of the BBVA Foundation for convening the 1st Spanish Workshop on Protected Areas Effectiveness Evaluation (SIAPA).

\section{Supplementary material}

To view supplementary material for this article, please visit http://dx.doi.org/10.1017/ S0376892915000065

\section{References}

Andam, K.S., Ferraro, P.J., Pfaff, A., Sánchez-Azofeifa, G.A. \& Robalino, J.A. (2008) Measuring the effectiveness of protected area networks in reducing deforestation. Proceedings of the National Academy of Science USA $\mathbf{1 0 5}$ 16089-16094.

Briggs, S.V. (2006) Integrating policy and science in natural resources: why so difficult? Ecological Management and Restoration 7: 37-39.

Carbonetti, B., Pomeroy, R. \& Richards, D.L. (2014) Overcoming the lack of political will in small scale fisheries. Marine Policy 44:295-301.

Cash, D.W., Clark, W.C., Alcock, F., Dickson, N.M., Eckley, N., Guston, D.H., Jäger, J. \& Mitchell, R.B. (2003) Knowledge systems for sustainable development. Proceedings of the National Academy of Science USA 100: 8086-8091.

CBD (1992) Text of the convention. United Nations Environment Programme, Nairobi, Kenya [www document].URL http://www.cbd.int/convention/text/default.shtml

CBD (2004) Programme of work on protected areas. United Nations Environment Programme, Nairobi, Kenya [www document]. URL http://www.cbd.int/protected/pow/ learn more/intro/

CBD (2010) COP10 Decision X/31. Protected areas. United Nations Environment Programme, Nairobi, Kenya [www document]. URL http://www.cbd.int/decision/cop/?id=12297

Coad,L., Leverington, F., Burgess, N.D., Cuadros, I.C., Geldmann, J., Marthews, T.R., Mee, J., Nolte, C., StollKleemann, S., Vansteelant, N., Zamora, C., Zimsky, M. \& Hockings, M. (2013) Progress towards the CBD protected area management effectiveness targets. PARKS 19(1): 13-24.

Cook, C.N., Mascia, M.B., Schwartz, M.W., Possingham, H.P. \& Fuller, R.A. (2013) Achieving conservation science that bridges the knowledge-action boundary. Conservation Biology 27: 669-678.

Cook, C.N. \& Hockings, M. (2011) Opportunities for improving the rigor of management effectiveness evaluations in protected areas. Conservation Letters 4: 372-382. 244 D. Rodríguez-Rodríguez et al. 
Cook, C.N., Hockings, M. \& Carter, R.W. (2010) Conservation in the dark? The information used to support management decisions. Frontiers in Ecology and the Environment 8: 181186.

Deke, O. (2008) Preserving biodiversity as a global public good: protected areas and international transfers. In: Environmental Policy. Instruments for Conserving Global Biodiversity, ed. D. Snower, pp. 185-342. Berlin and Heidelberg, Germany: Springer-Verlag.

Di Carlo, G., Romani, M., Webster, C., Guidetti, P. \& Claudet, J. (2013) Science for management workshop. Bridging Mediterranean scientists and resource managers. Workshop report. MedPAN Association, Marseille, France [www document]. URL http://www.maia-network.org/homepage/ news/520_1078/medpan_workshop_report_science_for_man agement

Dudley, N., ed. (2008) Guidelines for applying protected areas management categories. IUCN, Gland, Switzerland [www document]. URL http://cmsdata.iucn.org/downloads/ guidelines_for_applying_protected_area_management_categ ories.pdf

EC (1992) Environment. The Habitats Directive. European Commission, Brussels, Belgium [www document]. URL http://ec.europa.eu/environment/nature/legislation/habitatsdir ective/

Edgar, G.J., Stuart-Smith, R.D., Willis, T.J., Kininmonth, S., Baker, S.C., Banks, S., Barrett, N.S., Becerro, M.A., Bernard, A.T.F.,Berkhout, J.,Buxton, C.D., Campbell, S.J.,Cooper,A.T., Davey, M., Edgar, S.C., Försterra, G., Galván, D.E., Irigoyen, A.J.,Kushner, D.J.,Moura, R., Parnell, P.E., Shears, N.T., Soler, G., Elisabeth, M. A., Strain, E.M.A. \& Thomson, R.J. (2014) Global conservation outcomes depend on marine protected areas with five key features. Nature 506: 216-220.

Ervin, J. (2003) Protected area assessment in perspective. BioScience 53: 819-822.

Euser, A.M., Dekker, F.W. \& le Cessie, S. (2008) A practical approach to Bland-Altman plots and variation coefficients for $\log$ transformed variables. Journal of Clinical Epidemiology 61: 978-982.

Gabrié, C., Lagabrielle, E., Bissery, C., Crochelet, E., Meola, B., Webster, C., Claudet, J., Chassanite, A., Marinesque, S., Robert, P., Goutx, M. \& Quod, C. (2012) The status of marine protected areas in the Mediterranean Sea. MedPAN Collection. MedPAN and RAC/SPA, Marseille, France and Tunis, Tunisia [www document]. URL http://www.cbd.int/doc/meetings/mar/ebsaws-2014-03/other/ ebsaws- 2014-03-submission-medpan-1-en.pdf

Geldmann, J., Barnes, M., Coad, L., Craigie, I.D., Hockings, M. \& Burgess, N.D. (2013) Effectiveness of terrestrial protected areas in reducing habitat loss and population declines. Biological Conservation 161: 230-238.

Hewitt, R. \& Escobar, F. (2011) The territorial dynamics of fastgrowing regions: unsustainable land use change and future policy challenges in Madrid, Spain. Applied Geography 31: 650-667.

Hockings, M., Stolton, S. \& Dudley, N. (2006) Evaluating Effectiveness: a Framework for Assessing the Management of Protected Areas. Second edition. Gland, Switzerland \& Cambridge, UK:IUCN.

IUCN (2012) Protected areas green list. IUCN, Gland, Switzerland [www document]. URL http://www.iucn.org/ about/work/programmes/gpap_home/gpap_quality/gpap_gree nlist/

IUCN \& UNEP (2014) World database on protected areas. UNEP-WCMC, Cambridge, UK [www document]. URL http://www.wdpa.org/
Knight, A.T., Cowling, R.M., Rouget,M., Balmford, A., Lombard, A.T. \& Campbell, B.M. (2008) Knowing but not doing: selecting priority conservation areas and the researchimplementation gap. Conservation Biology 22: 610-617.

Leverington, F., Lemos, K., Courrau, J., Pavese, H., Nolte, C., Marr, M., Coad, L., Burguess, N., Bomhard, B. \& Hockings, M. (2010) Management Effectiveness Evaluation in Protected Areas. A Global Study. Second edition. Brisbane, Australia: University of Queensland.

MAGRAMA (2014) Red de Parques Nacionales. Seguimiento y evaluación [www document]. URL http://www.magrama .gob.es/es/red-parques-nacionales/plan-seguimientoevaluacion/\#

Mallarach, J.M., coord. (2008) Protegits, de fet o de dret? Primera avaluació del sistema d'espais naturals protegits de Catalunya. Institució Catalana d'Història Natural [www document]. URL http://ichn.iec.cat/Avaluacio_Espais.htm

MedPAN North (2013) A transnational cooperation project to enhance management effectiveness of marine protected areas in the Northern Mediterranean. World Wildlife Fund-France, Marseille, France. [www document]. URL http://www.medpan.org/documents/10180/0/MedPAN+North +Project+ presentation +brochure/495007a6-e350-40fb-88f0fabf0af8470b ?version= 1.0

Mora, C.\&Sale, P.F. (2011) Ongoing global biodiversity loss and the need to move beyond protected areas: a review of the technical and practical shortcomings of protected areas on land and sea. Marine Ecology Progress Series 434: 251-266.

Múgica, M., Martínez, C., Gómez-Limón, J., Puertas, J. \& Atauri, J.A. (2012) EUROPARC-España 2012. Anuario 2011 del estado de las áreas protegidas en España. Fundación Fernando González Bernáldez, Madrid, Spain [www document]. URL http://www.redeuroparc.org/img /publicaciones/ Anuario2011.pdf

Myers, N., Mittermeier, R.A., Mittermeier, C.G., da Fonseca, G.A.B. \& Kent, J. (2000) Biodiversity hotspots for conservation priorities. Nature 403: 853-858.

Naughton-Treves, L., Buck, M. \& Brandon, K. (2005) The role of protected areas in conserving biodiversity and sustaining local livelihoods. Annual Review of Environmental Resources 30: $219-252$.

Nolte, C., Leverington, F., Kettner, A., Marr, M., Nielsen, G. Bomhard, B., Stolton, S., Stoll-Kleemann, S. \& Hockings, M. (2010) Protected area management effectiveness assessments in Europe. A review of application, methods and results. University of Greifswald, Greifswald, Germany.

Olson, D.M. \& Dinerstein, E. (2002) The global 200: priority ecoregions for global conservation. Annals of the Missouri Botanical Garden 89: 199-224.

Prendergast, J.R., Quinn, R.M. \& Lawton, J.H. (1999) The gaps between theory and practice in selecting nature reserves. Conservation Biology 13: 484-492.

Pressey, R.L., Cabeza, M., Watts, M.E., Cowling, R.M. \& Wilson, K.A. (2007) Conservation planning in a changing world. Trends in Ecology and Evolution 22: 583-592.

Pullin, A.S., Knight, T.M., Stone, D.A. \& Charman, K. (2004) Do conservation managers use scientific evidence to support their decision-making? Biological Conservation 119: 245252 .

Rivas-Martínez, S., Cantó, P., Fernández-González, F., Pizarro, J.\& Sánchez-Mata, D. (1990) Biogeografía de la Península Ibérica, Islas Baleares y Canarias. Madrid, Spain: Universidad Complutense. Limited uptake of protected area evaluation systems 245

Rodríguez-Rodríguez, D. (2012) New issues on protected area management. In: Protected Area Management, ed. B. Sladonja, pp. 19-42. Intech, Rijeka,Croatia [www 
document].URLhttp://www.intechopen.com/books/protectedarea-management/newissues-on-protected-area-management

Rodríguez-Rodríguez, D. \& Martínez-Vega, J. (2012) Proposal of a system for the integrated and comparative assessment of protected areas. Ecological Indicators 23: 566-572.

Rodríguez-Rodríguez, D. \& Martínez-Vega, J. (2013a) Results of the implementation of the system for the integrated assessment of protected areas (SIAPA) to the protected areas of the Autonomous Region of Madrid (Spain). Ecological Indicators 34: 210-220.

Rodríguez-Rodríguez, D. \& Martínez-Vega, J. (2013b) Evaluación de la eficacia de las áreas protegidas. El Sistema de Evaluación Integrada de Áreas Protegidas (SEIAP). Resultados de la primera evaluación integrada de los espacios naturales protegidos de la Comunidad de Madrid. BBVA Foundation, Madrid, Spain [www document]. URL http://www.fbbva.es/TLFU/tlfu/esp/publicaciones/informes/ fichainforme/index.jsp?codigo $=722$
Spanish Government (2007a) Ley 42/2007, de 13 de diciembre, del Patrimonio Natural y de la Biodiversidad. Agencia Estatal Boletín Oficial del Estado, Madrid, Spain [www document]. URLhttps://www.boe.es/buscar/act.php?id = BOE-A-200721490

Spanish Government (2007b) Ley 5/2007, de 3 de abril, de la Red de Parques Nacionales. Agencia Estatal Boletín Oficial del Estado, Madrid, Spain [www document]. URL http://www.boe.es/boe/dias/2007/04/04/pdfs/A14639_ 14649.pdf

Tempesta,M.\&Otero,M.(2013) Guide for quick evaluation of management in Mediterranean MPAs. MedPAN Collection. World Wildlife Fund-Italy and IUCN-Centre for Mediterranean Cooperation, Rome, Italy, and Málaga, Spain [wwwdocument].URLhttps://portals.iucn.org/library/efil es/edocs/2013-018.pdf 